(ii) There was no stratified randomization in the study. The women were stratified at the time of analysis in to various groups based on the socioeconomic status to determine the influence of socioeconomic, status on haemoglobin levels and birth weight.

(ij) As explained above, it was a prospective study of pregnant mothers who went on to deliver a live baby and not a case control study.

c. A medical illness in mother constituted an exclusion criterion. We agree that multiple pregnancy and shorter interpregnancy interval $(<2$ years) are also known to influence the birth weight.

d. Haemoglobin estimation was done by cyanmeth haemoglobin method, a standardised method for haemoglobin estimation, in both the hospitals. The primary objective of the study was to see the correlation between maternal haemoglobin levels and birth weight in different socioeconomic groups and not matemal anaemia and birthweight. A haemoglobin value of less than $11 \mathrm{gm} / \mathrm{dl}$ at any time during gestation was labelled as anaemia. This study showed a significant inverse relationship of matemal haemoglobin concentration to birth weight, in agreement with the hypothesis that a higher blood viscosity with rising haemoglobin levels is responsible for sub optimal placental perfusion and decreased delivery of nutrients to the foetus

\section{Reference}

1. RaghuRaman TS, Parimala V, Bhalla M, Venkateshwar V, Iyengar A. A correlative study of matemal haemoglobin and birth weight. MJAFI 2001; 57:110-3.

Gp Capt TS RaghuRaman

Command Hospital (Air Force),Bangalore - 560007.

\title{
Aerosol Antisepsis
}

Dear Editor.

$\mathrm{T}$ his refers to the article "Aerosol antisepsis : an effective and user-friendly method of skin preparation." published in MJAFI [1]. We continue to use this method, successfully for preoperative skin preparation, at the same hospital where it was originally introduced. During the last two years we have faced the following difficulties and have tried to overcome them :

(a) The nozzle of the spray pump containing povidone iodine gets blocked and the quality of the spray is unsatisfactory. Weekly cleaning of the nozzle helps in overcoming this difficulty.

(b) Some patients have a bout of cough after povidone iodine is sprayed on the operative field. This is probably due to the inhalation of povidone iodine. Changing the direction of the spray, away from the patient's face and placing a screen before spraying reduces this problem considerably.

(c) In winter, spraying cold solution causes discomfort to the patients. Placing the spray pump in a hot water bath eliminates this problem.
An aerosol is defined as a suspension of extremely small liquid or solid particles in the air-diameter about $0.001 \mathrm{~mm}$. (2) Would it not be proper to refer to this method as antiseptic spray? The above mentioned difficulties are minor and can be easily overcome. On the whole this method of skin preparation is simple, effective, economical and user friendly. We have been using it for the last four years and recommend it's use in all operation theatres.

\section{References}

1. Mehrotra S, Bhot FB, Hemraj. Aerosol antisepsis : an effective and user friendly method of skin preparation. MJAFI 2002:58:95.

2. Harrison LM. The pocket medical dictionary. CBS publishers 1986.

Maj S Maurya*, Lt Col FB Bhot*

'Graded Specialist (Surgery), Military Hospital Yol Cantt, Kangra Valley - 176052 , Classified Specialist (Anaesthesia), INHS Asvini, Colaba, Mumbai 400005 .

\section{Military Environment nad Fecundity : A Study of Women in Uniform}

Dear Editor

$\mathrm{R}$ eference contemporary issue "Military Environment and Fecundity : A study of women in uniform" by Lt Col Rath etal, published in MJAFI 2002;58(1):44-6.

It is often worth considering the selective factors that may have led to "membership" in a particular group (or exclusion from it) especially if health status (in this case fertility) may have played a role. This has been called membership bias [1-3]. Since having children may keep women from work, working women may be relatively infertile. This has been termed the "infertile worker effect" [4]. Because of this selection bias one is not sure whether occupation outside home led to infertility or infertility led women to seek job outside home i.e. the direction of the cause - effect relationship (if any).

\section{References}

1. Sackett DL. Bias in analytic studies. Journal of chronic diseases 1979;32-51.

2. Schlessejman JJ, Stolley PD. Sources of bias. In:Schlesselman JJ, editor. Case - Control Studies; design, conduct, analysis. Oxford University Press New York, 1982:124-43.

3. Abramson JH, Abramson ZH. Survey methods in Community Medicine. $5^{\text {th }}$ ed. Churchill Livingstone; 1999;69-78.

4. Joffe M. Biases in research in reproduction and women's work. International Journal of Epidemiology; 1985:24:1 154.

Lt Col A Banerjee

Reader, Department of Preventive \& Social Medicine, Armed Forces Medical College, Pune - 411040. 